\title{
TEKHNIK MENYUSUI YANG BAIK DALAM MENURUNKAN KEJADIAN CRECKED NIPPLE
}

\author{
Arni Evayanti \\ Akademi Kebidanan Yayasan Pendidikan Konawe \\ E-mail: arnievayanti23@yahoo.com
}

\begin{abstract}
ABSTRAK
Masalah yang sering terjadi pada ibu menyusui adalah teknik menyusui yang tidak benar sehingga mengakibatkan crecked nipple (lecet puting susu) dimana bayi tidak menyusu sampai ke areola. Ibu perlu mengetahui teknik menyusui yang baik dan benar untuk mendukung keberhasilan menyusui. Salah satu penyebab kegagalan menyusui adalah disebabkan karena kesalahan ibu dalam memposisikan dan meletakkan bayi saat menyusui. Posisi menyusui dapat dilakukan dengan beberapa posisi. Tujuan penelitian adalah untuk mengetahui hubungan teknik menyusui dengan kejadian puting susu lecet pada ibu nifas di RSU Dewi Sartika Kota Kendari tahun 2017.Jenis penelitian yang digunakan adalah penelitian analitik dengan rancangan cross sectional. Populasi adalah semua ibu nifas yang memiliki bayi baru lahir di RSU Dewi Sartika Kota Kendari periode Januari - April tahun 2017 dengan jumlahsampel sebanyak 46 orang.Instrumen yang digunakan adalah kuesioner. Ada hubungan antara teknik menyusui dengan kejadian puting susu lecet $(p=0,000)$.. Responden dengan teknik menyusui baik mempunyai kemungkinan 6,85 kali untuk tidak mengalami puting susu lecet dibandingkan ibu dengan teknik menyusui kurang $(R P=6,85 C I 95 \%=1,41-33,28)$. Diharapkan pada petugas kesehatan dapat meningkatkan program konseling dan penyuluhan tentang teknik menyusui yang benar
\end{abstract}

Kata Kunci : Cracked nipple (Puting Susu lecet); Tehnik Menyusui

\section{THE EFFECTIVENESS OF GOOD BREASFEEDING TECHNIQUES IN REDUCING THE INCIDENCE OF CRECKED NIPPLE}

\begin{abstract}
The problem that often occurs in nursing mothers is improper breastfeeding, resulting in nipple blisters, where the baby does not suckle to the areola. Mothers need to know good and correct breastfeeding techniques to support successful breastfeeding. One of the causes of failure to breastfeed is caused by the mother's mistake in positioning and putting the baby while breastfeeding. The position of breastfeeding can be done in several positions. The aim of this study was to determine the relationship between breastfeeding techniques and the incidence of cracked nipple in postpartum mothers in Dewi Sartika General Hospital Kendari City. The type of research used was analytical research with a cross sectional design. The population was all postpartum mothers who have newborns at Dewi Sartika General Hospital Kendari City for the period of January-April 2017 with a total sample of 46 people. The instruments used were questionnaires. There is a relationship between the technique of breastfeeding and the incidence of scuffed nipples $(p=0,000)$. Respondents with a good breastfeeding technique have a probability of 6.85 times not to experience blisters nipples compared to mothers with less breastfeeding techniques ( $\mathrm{RP}=6.85 \mathrm{CI} 95 \%=1.41-33.28)$. It is expected that health workers can improve counseling and counseling programs about correct breastfeeding techniques
\end{abstract}

Keywords: Cracked nipple; Breastfeeding Techniques. 


\section{Pendahuluan}

Masalah yang sering terjadi pada ibu menyusui adalah teknik menyusui yang tidak benar sehingga mengakibatkan lecet puting susu, dimana bayi tidak menyusu sampai ke areola. Sebagian besar areola dalam menyusui usahakan dapat masuk ke mulut bayi, sehingga puting susu berada dibawah langit-langit dan lidah bayi akan menekan ASI keluar dari tempat penampungan ASI yang terletak di bawah areola (Kristiyansari, 2009).

Masalah tersering di Indonesia dalam menyusui adalah puting susu lecet sekitar 57\% dari ibu menyusui didapatkan pernah menderita kelecetan pada putingnya. Hal ini disebabkan kesalahan dalam teknik menyusui. Puting susu lecet yang disebabkan oleh kesalahan dalam teknik menyusui yaitu bayi tidak menyusu sampai kalang payudara, sehingga gusi bayi tidak menekan pada daerah laktiferus, sedangkan pada ibunya akan terjadi nyeri/kelecetan pada puting susunya (Soetijiningsih, 2013).

Puting susu yang lecet juga disebabkan oleh moniliasis (infeksi yang disebabkan oleh monilia yang disebut candida) pada mulut bayi yang menular pada puting susu, iritasi akibat membersihkan puting dengan sabun, lotion, krim, alkohol, bayi dengan tali lidah pendek (frenulum lingue) sehingga sulit menghisap sampai areola dan hanya sampai puting dan cara menghentikan menyusu kurang hati-hati. Agar laktasi berjalan baik diperlukan manajemen yang baik dalam laktasi, meliputi perawatan payudara, praktek menyusui yang benar, serta dikenalinya masalah dalam laktasi dan penatalaksanaannya (Mansjoer, 2009).

Berdasarkan hasil studi pendahuluan yang dilakukan di RSU Dewi Sartika Kota Kendari diperoleh data jumlah ibu nifas periode Januari - April 2017 sebanyak 46 orang. Hasil observasi terhadap 10 orang ibu nifas diperoleh 6 ibu mengalami puting susu lecet di mana 4 orang telah melakukan teknik menyusui yang benar, sedangkan 2 orang tidak melakukan teknik menyusui yang benar. Empat ibu nifas yang tidak mengalami puting susu lecet setelah dilakukan observasi dimana 2 ibu melakukan teknik menyusui dengan benar dan 2 ibu tidak melakukan teknik menyusui dengan dengan benar. Sebelumnya ibu nifas telah mendapatkan informasi tentang teknik menyusui yang benar dari bidan di rumah sakit.

\section{Tinjauan Teoritis}

Menyusui merupakan suatu aktivitas yang bisa mendatangkan kebahagiaan tersendiri bagi ibu, yang memang menjadi kodratnya. Untuk mendukung keberhasilan menyusui, perlu mengetahui teknik menyusui yang baik dan benar. Salah satu penyebab kegagalan menyusui adalah disebabkan karena kesalahan ibu dalam memposisikan dan meletakkan bayi saat 
menyusui. Posisi menyusui dapat dilakukan dengan beberapa posisi. Cara menyusui yang tergolong biasa dilakukan adalah dengan duduk, berdiri, atau berbaring. Menyusui dengan teknik yang tidak benar dapat mengakibatkan puting payudara lecet. Salah satu faktor yang sering dilakukan saat menyusui adalah posisi menyusui yang belum tepat sehingga mengganggu produksi dan transfer Air Susu Ibu (ASI) ke bayi (Khasanah, 2011).

Cara menyusui yang benar dengan hisapan bayi yang kuat sampai seluruh bagian besar kalang payudara merangsang puting susu dan ujung syaraf sensoris yang berfungsi sebagai reseptor mekanik. Rangsangan yang berasal dari hisapan bayi akan dilanjutkan ke hipotalamus sehingga akan merangsang keluarnya oksitosin sehingga pengeluaran ASI dilaksanakan (Soetijiningsih, 2013).

Sebelum menyusui, berbaringlah selama 10-15 menit dan tenangkan pikiran. Perasaan marah, jengkel, atau tegang akan mempengaruhi produksi ASI sehingga hanya keluar sedikit. ASI dibentuk didalam kelenjar-kelenjar susu jauh didalam payudara, kemudian dibawa oleh saluran-saluran kecil ke tempat areola, yaitu lingkaran yang berwarna gelap di sekeliling luar puting. Oleh karena itu, jika bayi hanya menghisap di puting saja maka ASI yang keluar tidak cukup banyak. Masukkan juga areola kedalam mulutnya sehingga tekanan gusinya akan mendorong timbunan ASI dalam areola ini kearah puting. Sementara itu, saluran-saluran akan mengalirkan lagi ASI dari tempat pembentukannya di kelenjar kedalam tempat penampungannya. Kalau hanya puting yang masuk mulut, bayi harus menghisap dengan kuat dan menyebabkan puting mejadi lecet (Khasanah, 2011 ).

Menurut Ambarwati dan Wulandari (2009), puting susu terasa nyeri bila tidak ditangani dengan benar akan menjadi lecet, umumnya menyusui akan menyakitkan dan kadang mengeluarkan darah. Puting lecet adalah masalah menyusui di mana puting mengalami cedera karena lecet, kadang kulitnya sampai terkelupas atau luka berdarah (sehingga ASI menjadi berwarna merah muda).

Menurut Suherni (2009), penyebab puting susu lecet, yaitu:

1. Bayi menyusu tidak sampai ke kalang payudara, karena kesalahan dalam teknik menyusui;

2. Puting susu terpapar (ada sisa) bahan-bahan seperti sabun, krim alkohol, karena mencuci puting susu menggunakan bahan-bahan tersebut;

3. Penyakit moniliasis pada puting susu yang berasal dari moniliasis pada mulut bayi yang menular ke puting susu; 
4. Frenulum lidah bayi pendek, sehingga bayi susah menghisap sampai ke kalang payudara dan karenanya hisapan hanya sampai ke puting susu;

5. Teknik ibu menghentikan bayi menyusui kurang tepat.

\section{Metode Penelitian}

Penelitian ini telah dilaksanakan di RSU Dewi Sartika Kota Kendari pada bulan November Tahun 2017. Jenis penelitian yang digunakan adalah penelitian analitik dengan rancangan cross sectional. Populasi dalam penelitian ini adalah semua ibu nifas yang memiliki bayi baru lahir di RSU Dewi Sartika Kota Kendari periode Januari - April tahun 2017, jumlah sampel 46 orangdengan metode pengambilan sampel teknik total sampling. Instrumen yang digunakan kuesioner. Variabel yang akan diukur yaitu variabel independen adalah tehnik menyusui dan variabel dependen adalah putting susu lecet.

\section{Hasil Penelitian}

Analisis bivariat dilakukan untuk melihat hubungan antara variabel terikat (puting susu lecet) dengan variabel bebas (teknik menyusui). Uji statistik yang digunakan Chi-Square pada tingkat kepercayaan $(\alpha=0,05)$ dengan Confidence Interval (CI) $95 \%$.

Tabel 1. Hubungan Teknik Menyusui dengan Kejadian Puting Susu Lecet di RSU Dewi Sartika Kota Kendari Tahun 2017.

\begin{tabular}{|c|c|c|c|c|c|c|c|c|c|}
\hline \multirow{3}{*}{ No } & \multirow{3}{*}{$\begin{array}{l}\text { Teknik } \\
\text { Menyusui }\end{array}$} & \multicolumn{4}{|c|}{ Kejadian Puting Susu Lecet } & & & \multirow{3}{*}{$p$} & \multirow{3}{*}{$\begin{array}{l}\text { OR } \\
(\mathbf{9 5 \%} \\
\text { CI) }\end{array}$} \\
\hline & & \multicolumn{2}{|c|}{ Lecet } & \multicolumn{2}{|c|}{ Tidak Lecet } & \multicolumn{2}{|c|}{ Jumlah } & & \\
\hline & & $\mathbf{n}$ & $\%$ & $\mathbf{n}$ & $\%$ & $\mathbf{N}$ & $\%$ & & \\
\hline 1 & Baik & 1 & 9.1 & 10 & 90.9 & 11 & 100 & 0,000 & 6,85 \\
\hline 2 & Cukup & 6 & 42.86 & 8 & 57.14 & 14 & 100 & & $(1,41-$ \\
\hline 3 & Kurang & 20 & 95.23 & 1 & 4.77 & 21 & 100 & & $33,28)$ \\
\hline & Jumlah & 27 & 59 & 19 & 41 & 46 & 100 & & \\
\hline
\end{tabular}

Sumber : Data Primer, diolah November 2017

Tabel 1 memberikan gambaran bahwa responden dengan teknik menyusui baik sebagian besar tidak mengalami puting susu lecet sebanyak 10 orang $(90.9 \%)$, responden dengan teknik menyusui cukup sebagian besar tidak mengalami puting susu lecet sebanyak 8 orang $(57.14 \%)$ dan responden dengan teknik menyusui kurang baik sebagian besar mengalami puting susu lecet sebanyak 20 orang (95.23\%). 
Hasil uji statistik menggunakan uji chi square diperoleh nilai $p=0,000<0,05$ sehingga Ha diterima, berarti ada hubungan yang signifikan antara teknik menyusui dengan kejadian puting susu lecet. Hasil analisis diperoleh nilaiOR $=6,85$ (95\% CI = 1,41-33,28), artinya ibu dengan teknik menyusui baik mempunyai peluang 6,85 kali untuk tidak mengalami puting susu lecet dibandingkan ibu dengan teknik menyusui kurang.

\section{Pembahasan}

Hasil penelitian tentang hubungan teknik menyusui dengan kejadian puting susu lecet, maka diperoleh hasil ada hubungan yang signifikan antara teknik menyusui dengan kejadian puting susu lecet. Hasil penelitian ini sejalan dengan hasil penelitian yang dilakukan oleh Frizka (2013), menyatakan bahwa ada hubungan yang bermakna antara teknik menyusui dengan kejadian puting susu lecet dengan nilai $p=0,000$. Sama halnya dengan penelitian yang dilakukan oleh Nia Apriyani (2013), yang menyimpulkan bahwa ada hubungan yang signifikan antara teknik menyusui dengan kejadian puting susu lecet dengan nilai $p=0,001$.

Kegagalan menyusui sering kali disebabkan karena kesalahan memposisikan dan melekatkan bayi (Suradi, 2008). Jika bayi tidak melekat dengan sempurna atau jika puting terus-menerus tergesek oleh lidah atau langit-langit bayi, puting dapat mengalami abrasi atau luka. Puting yang lecet sangat menyakitkan dan dapat menyebabkan perdarahan, jika putingyang lecet tidak segera diobati dapat menyebabkan mastitis dan abses di payudara. Selain menyebabkan puting susu lecet tehnik menyusui yang salah juga dapat mengakibatkan ASI tidak keluar optimal sehingga mempengaruhi produksi ASI selanjutnya atau bayi enggan menyusu (Proverawati, 2010).

Tehnik menyusui yang benar sangat diperlukan oleh ibu nifas, terutama untuk mencegah kejadian puting lecet, oleh karena itu tindakan tenaga kesehatan untuk menambah pengetahuan ibu mengenai tehnik menyusui adalah dengan memberikan penyuluhan mengenai tehnik menyusui dan tindakan yang dapat dilakukan ibu adalah mencari informasi mengenai tehnik menyusui yang benar.

\section{Kesimpulan}

Ibu dengan teknik menyusui baik mempunyai kemungkinan 6,85 kali tidak mengalami crecked nipple (putting susu lecet) dibandingkan ibu dengan teknik menyusui kurang. 


\section{Saran}

Diharapkan pada petugas kesehatan dapat meningkatkan program konseling dan penyuluhan tentang teknik menyusui yang benar. Diharapkan kepada ibu agar dapat menyusui bayi dengan posisi yang benar agar tidak terjadi lecet pada puting susu. Diharapkan untuk melakukan pengembangan dari penelitian ini dengan melakukan penelitian lebih lanjut dengan menggunakan metode yang berbeda dengan hubungan teknik menyusui dengan kejadian puting susu lecet.

\section{Daftar Pustaka}

Ambarwati dan Wulandari. (2009). Asuhan Kebidanan Nifas. Jogjakarta : Mitra Cendikia Offset.

Frizka Indarningtyas Nur Pratiwi. (2013). Hubungan Teknik Menyusui dengan Kejadian Putting Susu Lecet Pada Ibu Nifas di Wilayah Puskesmas Sekaran. Program Studi D IV Kebidanan Fakultas Kedokteran. Surakarta : Universitas Sebelas Maret.

Khasanah. (2011). ASI atau Susu Formula ya?. Jogjakarta : Flash Book.

Kristiyansari. (2009). ASI, Menyusui \& SADARI. Yogyakarta : NuhaMedika.

Mansjoer. (2009). Kapita Selekta Kedokteran, Jakarta : Media Aesculapius.

Nia Apriyani. (2013). Pengetahuan Ibu Nifas tentang Teknik Menyusui dengan Kejadian Puting Susu Lecet di Wilayah Kerja Puskesmas Buaran Kabupaten Pekalongan. Program Studi Diploma III Kebidanan. Stikes Muhammadiyah PekajanganPekalongan.

Proverawati, dkk. (2010). Kapita Selekta ASI dan Menyusui. Yogyakarta : Nuha Medika.

Soetjiningsih.(2013). Tumbuh Kembang Anak. Jakarta : Rineka Cipta.

Suherni, dkk. (2009). Perawatan Masa Nifas. Jogjakarta : Fitramaya.

Suradi, Rulina. (2008). Buku Bacaan Manajemen Laktasi. Jakarta : Perinasia. 